\title{
ACTIVE SUPPRESSION OF AERODYNAMIC INSTABILITIES IN THE AXIAL FLOW COMPRESSORS
}

\author{
Ahmed Sayed Hassan \\ Mechanical Engineering Department, Assiut, University, Assiut, Egypt.
}

(Received August 2, 2006 Accepted October 9, 2006)

\begin{abstract}
Aerodynamic instabilities due to rotating stall initiation and surge trigger in the axial flow compressors were investigated using different mathematical models. Limit of stability of the rotating stall was detected using simple model that considers transport of energy by the rotor wakes passing through the stator. Active suppression of the aerodynamic instabilities in the axial flow compressors were demonstrated using mechanical compensated system with controlled plenum simultaneously with air injection through reed valve. A nonlinear controller based on a bifurcation theory was used to design feedback control system for eliminating surge and rotating stall as well hysteresis. The bifurcation analysis was performed to determine the effect of throttle gain on the compressor limit of stability and then modifying the throttle characteristic to eliminate hysteresis and suppresses surge. The Moore-Greitzer model was extended to include the influences of the air injection on the axial flow compressors performance characteristics and to enhance the limit of stabilities of both the stall and the surge. Comparisons of the present theoretical results with the available previous experimental and theoretical results were carried out.
\end{abstract}

KEYWORDS: Axial flow compressors, Rotating stall, surge, Limit of stability.

\section{1- INTRODUCTION}

The axial flow compressors are widely used in various engineering applications. Their functions are to increase the pressure of the fluid and they are designed to operate in steady axisymmetric flow. As one decreases the flow rate through the compressor, the pressure rise increases and this improves the performance. Below a critical value of the flow rate, phenomena of aerodynamic instabilities occur, which are classified as (deep) surge, rotating stall and classic surge. However, various efforts to either avoid or control of those phenomena have been studied [1-26]. Rotating stall is the limit cycle resulting from higher-order, rotating-wave disturbances, while surge is a largeamplitude, low frequency (compared to rotating stall) oscillation of the total, annulusaveraged mass flow rate. Aerodynamic instabilities in axial flow compressors and possibilities to suppress them with feedback control are being investigated in an increasing number of theoretical studies often accompanied by experiments. Some of 
the available control approaches can be divided into two main categories, linearization and linear perturbation models e.g., [1-5] and Bifurcation analysis e.g., [6-9]. Experiments were performed by Freeman et al. [10] show that the stable operating range of axial compressors was increased by $25 \%$ with using a feedback controller.

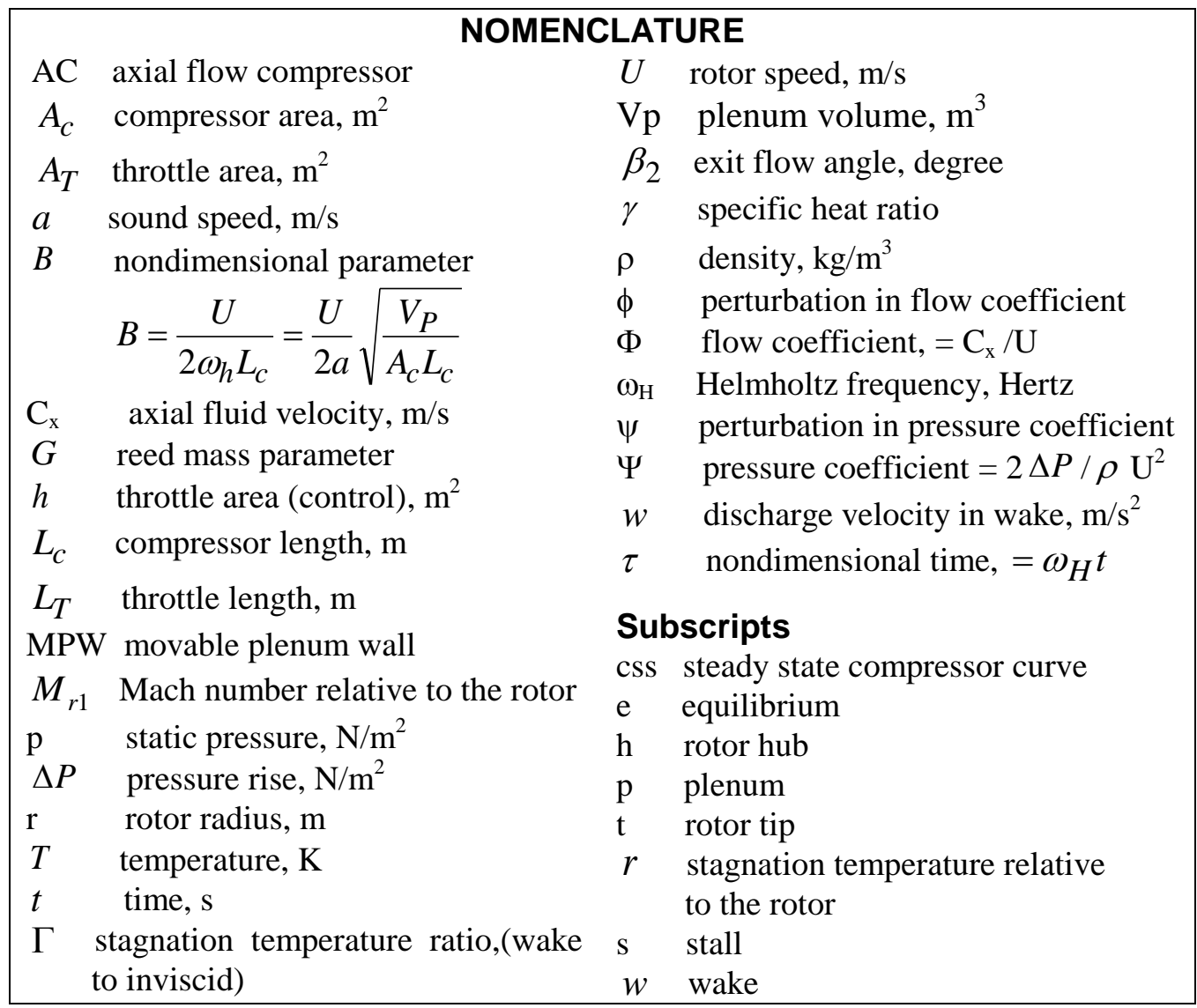

References [11-13] present output-feedback controllers for axial-flow compressors. Chaturvedi and Bhat [19], deals with the use of feedback control to prevent hysteresis and surge in axial-flow compressors. Surge suppression using controlled plenum wall in centrifugal compressors was investigated [20-21] and with centrifugal blower [22]. In addition, considerable research has been done on the application of feedback control techniques to the problem of eliminating hysteresis and surge oscillations in axial flow compressors [23]. Rotating stall was controlled using pulsed air injection that is distributed around the annulus of the flow compressor [26]. Protz [27] and Yeung [28] have investigated air injection controllers, and Weigl et al. [29], Protz [30], D'Andrea et al. [31] have carried out successful experiments. However, most of the control-oriented studies published during the last decade employ simplified versions of an ordinary partial differential equation compressor model by Moore and Greitzer [3] because of its remarkable ability to qualitatively describe and predict compressor operation. 
In the present study, initiations of rotating stalls and limits in the axial flow compressors were investigated. Active suppression of the aerodynamic instabilities in the axial flow compressors were established using mechanical compensated system with controlled plenum simultaneously with air injection through reed valve. The bifurcation analysis was performed to determine the effect of throttle gain on the compressor limit of stability and then modifying the throttle characteristic to eliminate hysteresis and suppresses surge. The Moore and Greitzer model was extended to include the effects of air injection on the compressor performance and to increase the limit of stability.

\section{DETECTION OF ROTATING STALL IN AXIAL COMPRESSORS}

Previous investigators [15] show that the stagnation temperature at the exit from stator of the axial flow compressor is not uniform and substantial stagnation temperature wake can exist downstream of the stators. In addition, when the axial flow compressor, shown in Fig. 1, operates at low flow rates, the rotor wake fluid has energy in excess of the inviscid flow, which the pressure side of the stator collects it. If the transport of energy by the rotor wakes passing through the stators is considered, the static and stagnation temperatures of the rotor wake fluid $T_{2 w}, T_{o 2 w}$ can be written respectively as:

$$
\begin{aligned}
& T_{2 w}=\Gamma_{2 w} T_{r 1}-w_{2}^{2} / 2 C p \\
& T_{o 2 w}=\Gamma_{2 w} T_{r 1}+U^{2}\left(1-2 w_{2} \sin \beta_{2} / U\right) / 2 C p
\end{aligned}
$$

where, $\Gamma$ is the stagnation temperature ratio $\Gamma, w$ is the discharge velocity in the wake relative to the blade and $\beta_{2}$ is the exit flow angle measured from the axial direction.

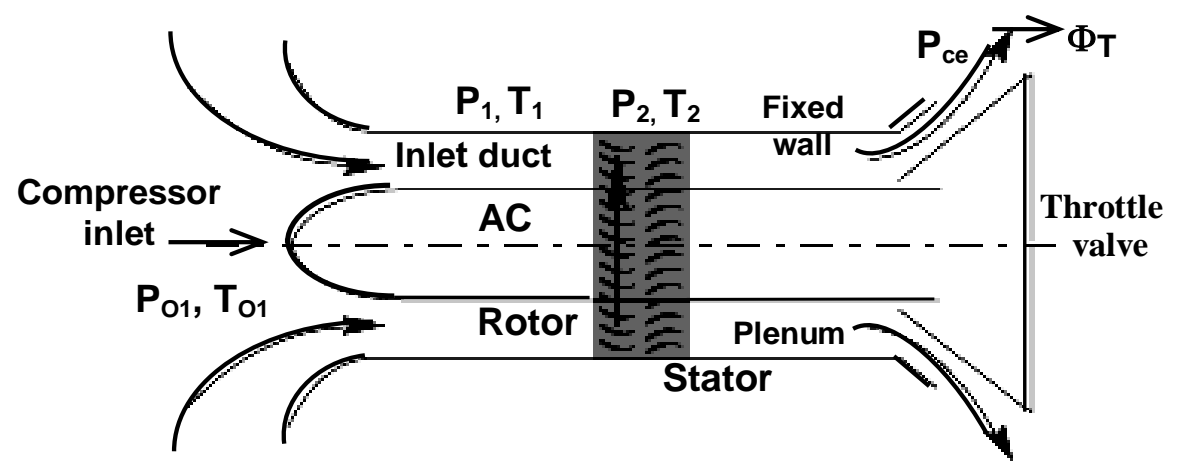

Fig. 1: Axial flow compressor of a fixed wall plenum.

Using definition of the tangential Mach number: $M_{t}=\sqrt{U^{2} / C p T(\gamma-1)}$, the stagnation temperature of the rotor wake fluid in Eq.(2) relative to inlet temperature can be written as:

$$
\Gamma_{o 2 w}=\Gamma_{2 w} \Gamma_{r 1}+(\gamma-1) M_{t 1}^{2}\left[1-\left(2 w_{2} \sin \beta_{2} / U\right)\right] / \gamma
$$

Whereas, the stagnation temperature for inviscid flow is: 


$$
\Gamma_{o 2 W}=\Gamma_{r 1}+(\gamma-1) M_{t 1}^{2}\left[1-\left(2 W_{2} \sin \beta_{2} / U\right)\right] / \gamma
$$

Substitute $\Gamma_{r 1}=1+0.5(\gamma-1) M_{r 1}^{2}$, where $M_{r 1}$ is the Mach number relative to the rotor. The wake, therefore, has an excess of stagnation temperature over that of the inviscid flow, given by:

$$
\Delta \Gamma_{o 2}=\left(\Gamma_{2 w}-1\right)\left[1+0.5(\gamma-1) M_{r 1}^{2}\right]+(\gamma-1) M_{t 1}^{2} \sin \beta_{2}\left(W_{2}-w_{2}\right) / U
$$

Equation 5 indicates that the wakes may have a deficiency of stagnation temperature, conditional on the magnitude of $\sin \beta_{2}\left(W_{2}-w_{2}\right) / 2 U$. This means a recirculating flow (rotating stall) of stagnation temperature is expected to be distributed across the passage rather than appearing in the stator wake that is called rotor wake fluid.

Similarly, the stagnation pressure of the wake is given by:

$$
P_{o 2 w}=P_{2}\left\{1+\left[\left(w_{2} \cos \beta_{2}\right)^{2}+\left(U-w_{2} \sin \beta_{2}\right)^{2}\right] / 2 C p T_{2}\right\}^{\gamma /(\gamma-1)}
$$

hence

$$
\frac{P_{o 2 w}}{P_{2}}=\left[\left(1+\frac{\gamma-1}{2} M_{r 1}^{2}\right)\left[\frac{1+\left(w_{2} / U\right)^{2}-2\left(w_{2} / U\right) \sin \beta_{2}}{\Gamma_{2 w}\left[1+0.5(\gamma-1) M_{r 1}^{2}\right]-0.5(\gamma-1) M_{r 1}^{2}\left(w_{2} / U\right)^{2}}\right]\right]^{\gamma /(\gamma-1)}
$$

When, $0.5(\gamma-1) M_{r 1}^{2}<<1$ and $\Gamma_{2 w}=1$ then, Eq. (6) becomes:

$$
\frac{P_{o 2 w}}{P_{2}}-\frac{P_{o 2 W}}{P_{2}}=\left[M_{t 1}^{2}(\gamma-1)\left(\frac{W_{2}-w_{2}}{U}\right)\left[\sin \beta_{2}-\frac{W_{2}+w_{2}}{2 U}\right]\right]^{\gamma /(\gamma-1)}
$$

Equation (7) indicates that the wake have an excess or a deficiency of stagnation pressure, depending on the relative magnitude of $\left(W_{2}+w_{2}\right) / 2 U$ and $\sin \beta_{2}$. Therefore, it is expected a recirculating flow or rotating stall of stagnation pressure to be distributed across the passage rather than appearing in the stator wake. That is, the energy transport inside the stator leads to impingement of the wake flow on the stator pressure surface that leads to recirculation or rotating stall inside the stator passages. This concluded that, the rotor and stator wakes are the main cause of rotating stall initiation. However, this method for rotating stall detection does not take the pressure losses that directly effects on compressor performance characteristic. Therefore, a simple model that considered the pressure losses similar to Le et al. [16] is used for description of rotating stall initiation in the axial flow compressor. This reference does not consider effect of the incidence loss on the compressor pressure coefficient. The radial equilibrium equation at rotor down stream can be written as:

$$
d p_{2}=\rho \omega^{2}\left(1-\phi \tan \beta_{2}\right)^{2} r d r
$$

where $\phi$ is the compressor local flow coefficient. When the compressor operates at condition different from those of design conditions, the flow is accomplished with incidence losses that appear to be zero at compressor design operating conditions. The loss in the compressor pressure coefficient due to incidence is $0.5 \rho U^{2} C_{i} \phi^{2}$ where, $C_{i}$ is the incidence loss coefficient that depends on the incidence angle. The Bernoulli 
and Euler equations those corrected for losses that give the value of the down stream pressure can be written as:

$$
p_{2}=P_{1}+0.5 \rho U^{2}\left[1-\phi^{2}\left(1+\tan ^{2} \beta_{2}\right)-C_{i} \phi^{2}-C_{f}\left(1+\phi^{2}\right)-C_{s h}\left(\phi-\phi_{o}\right)^{2}-C_{f w} \phi^{2}\right]
$$

where $C_{f}$ is the rotor blade loss coefficient, $C_{s h}$ is the loss coefficient at stall condition and $C_{f w}$ is the wall loss coefficient. Those were taken similar to [16] $C_{f}=0.075, C_{s h}=3$ and $C_{f w}=0.25$. Integrating of equation deduced from Eqs.(8) and (9) by removing of $p_{2}$, gives the radial distribution of the local flow coefficient $\phi$ :

$$
\begin{gathered}
{\left[\phi\left(4.475+\tan ^{2} \beta_{2}\right)-3 \phi_{o}\right] \frac{d \phi}{d r}+\left[\tan \beta_{2} \frac{d \tan \beta_{2}}{d r}+4.475+2 \tan ^{2} \beta_{2}\right] \frac{\phi^{2}}{r}} \\
-\left[3 \frac{d \phi_{o}}{d r}+\frac{2}{r}\left(\tan \beta_{2}+3 \phi_{o}\right)\right] \phi+3 \phi_{o} \frac{d \phi_{o}}{d r}+\frac{0.075}{r}+\frac{1}{r}\left(3 \phi_{o}^{2}\right)=0
\end{gathered}
$$

The overall mass flow coefficient that gives the constant of integration can be written as:

$$
\Phi=2 \int_{r_{h}}^{r_{t}} \phi r^{2} d r /\left[r_{t}\left(r_{t}^{2}-r_{h}^{2}\right)\right]
$$

It can be seen, without integrating of Eq.(10), that since the coefficient of $d \phi / d r$ vanishes when at some radius, the condition $\phi_{S}=3 \phi_{o} /\left(4.475+\tan \beta_{2}^{2}\right)$ is satisfied; for values of the overall mass flow coefficient $\Phi$ smaller than the corresponding stall mass flow coefficient $\Phi_{s}$, no continuous solution of Eq.(10) can be obtained in the domain $r_{h}<r<r_{t}$. The equation that describes the compressor characteristic curve of compressor used in the present model is illustrated in Fig.2. However, Eq.(9), gives the physical meaning of this result: Since the derivative $d p_{2} / d \phi$ vanishes also for, $\phi=\phi_{s}$. The stall limit given by this analysis appears as the ultimate mass flow rate for which radial pressure equilibrium can be obtained in a continuous way. The experimental and theoretical results of Le et al. [16] are transferred to the compressor characteristic curves $(\Psi-\Phi)$ as shown in Fig. 2.

The present theoretical analyses that include the incidence loss beside the other mentioned losses are shown in the figure. It is clear in the figure that there is an acceptable agreement for the present analysis in respect to the theoretical data of Le et al. [16] in respect of stall limit. The results of the present analysis beside the data from the experimental and theoretical of Le et al. [16] confirmed that, the causes of rotating stall initiation are the separation of the flow from the rotor and stator blades. This concluded that the present analysis could be used for detection of stall limit in the axial flow compressor characteristic. Figure 2 shows some differences between the experimental and theoretical resells of Le et al. [16] in respect of the limit of stability, this may be attributed to the assumptions of his theoretical work or errors of measuring of stall initiations or detections. 


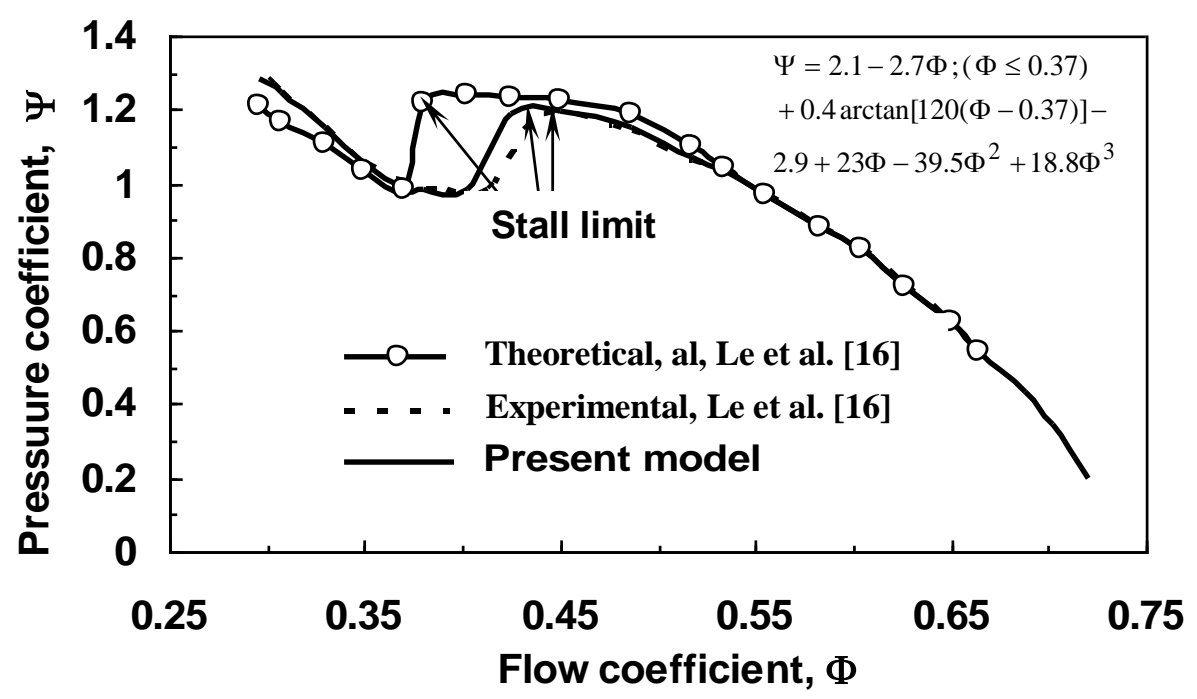

Fig. 2: Stall limit of the present model, experiment and Le et al. [16].

\section{MODELS AND DETECTIONS OF ROTATING STALL AND SURGE}

\subsection{Compression System Model without Controller}

Consider the compression system model that consists of an axial flow compressor modeled as an actuator disk, inlet or upstream annular duct, downstream annular duct (fixed plenum wall) and a throttle valve as shown in Fig.1. The momentum, continuity throttle and the compressor transient response equations those describing the compression system with fixed plenum wall are:

$$
\begin{aligned}
& l_{c} \frac{d \dot{m}}{d t}=\Delta P_{c}-\Delta P_{p} \\
& \frac{\rho V_{p}}{\gamma P} \frac{d P_{p}}{d t}=\dot{m}_{c}-\dot{m}_{T} \\
& l_{T} \frac{d \dot{m}}{d t}=\Delta P_{p}-\Delta P_{T} \\
& \tau \frac{d \Delta P_{c}}{d t}=\Delta P_{c s s}-\Delta P_{c}
\end{aligned}
$$

where $P_{c s s}$ is steady state measured compressor curve of Greitzer [17]. Eq.(13) is nondimensionalized as follows:

$$
\begin{aligned}
& \frac{d \Phi_{c}}{d \tau}=B\left[\Psi_{c}\left(\Phi_{c}\right)-\Psi_{p}\right] \\
& \frac{d \Psi_{p}}{d \tau}=\frac{1}{B^{2}}\left[\Phi_{c}-\Phi_{T}\left(\Psi_{p}\right)\right]
\end{aligned}
$$




$$
\begin{aligned}
& \frac{d \Phi_{T}}{d \tau}=\lambda B\left[\Psi_{p}-\Psi_{T}\left(\Phi_{T}\right)\right] \\
& \frac{d \Psi_{c}\left(\Phi_{c}\right)}{d \tau}=\frac{1}{\tau}\left[\Psi_{o}\left(\Phi_{c}\right)-\Psi_{c}\left(\Phi_{c}\right)\right]
\end{aligned}
$$

where, $\Psi_{c}$ is the axisymmetric compressor characteristic relating steady state values of the pressure rise to steady state values of mass flow, $\Phi_{c}$ is the annulus averaged mass flow coefficient (axial velocity divided by compressor speed), Greitzer- $B$ parameter, $\quad B=U /\left(2 \omega_{H} L_{c}\right), \quad \mu=\sigma /\left(\omega_{H} L_{c}\right), \quad \lambda=x_{c} / x_{T}, x_{c}=L_{c} / A_{c}$, $x_{T}=L_{T} / A_{T}$ and the subscripts $c, p, T$ are the compressor, plenum and throttle respectively.

\subsection{Compressor and Throttle Characteristics}

The throttle characteristic $\Phi_{T}$ is modeled as: $\Phi_{T}\left(\Psi_{P}\right)=\sqrt{h \Psi_{p}}-1$, where $h$ is a coefficient (control) depending on the throttle valve area. $\Psi_{p}$ is the plenum pressure. The compressor characteristic $\Psi_{c}\left(\Phi_{c}\right)$ is taken as a polynomial function (or cubic curve) as described by Mansoux et al [18],

$$
\begin{aligned}
\Psi_{c}\left(\Phi_{c}\right)= & 12.117 \Phi_{c}^{2}-2.423 \Phi_{c}+0.221 ; \Phi_{c} \leq 0.1 \\
& -49.62 \Phi_{c}^{3}+39.509 \Phi_{c}^{2}-6.413 \Phi_{c}+0.395 ; 0.1<\Phi_{c} \leq 0.4 \\
& -10.0695 \Phi_{c}^{2}+9.43 \Phi_{c}-1.184 ; \Phi_{c}>0.4
\end{aligned}
$$

Figure 3 shows an axial flow compressor characteristic curve during the stable and unstable operation conditions. This figure includes the compressor characteristic (solid line in the path from point $\mathrm{F}$ to just before point $\mathrm{B}$ ) represents all stationary solutions for Eq.(14a). The throttle characteristic starting at the origin represents all stationary solutions of Eq.(14b). As the throttle valve is slowly closed, the throttle characteristic becomes steeper, the intersection point between $\Psi_{\mathrm{C}}(\Phi)$ and $\Psi_{\mathrm{T}}(\Phi)$ changes, and the equilibrium operating point of the compressor moves from high flow rate to low flow rate. Since $\Phi_{c}=$ zero is a stationary solution for Eq.(15), that concludes that the intersection of the two curves is a stationary solution (called design flow) for all system that represents by Eqs (14a, 14b and 15). While, surge is a limit cycle in the two ordinary differential Eqs.(14a and 14b).

However, when the compressor operates at the design mass flow rate, the flow through it is axisymmetric and stable. As the flow decreases, the pressure goes on increasing until point $\mathrm{A}$ is reached where abrupt transition occurs to point $\mathrm{B}$ into unsteady operations at point $\mathrm{C}$. There is severe hysteresis between steady axisymmetric flow and rotating stall. At point $\mathrm{C}$, two different phenomena of rotating stall or surge can be occurred depending on the throttle characteristic. A typical surge cycle is shown in Fig. 3. This cycle starts at point B where the flow becomes unstable, then jumps to approximately zero flow rates at the points $\mathrm{D}$ and $\mathrm{E}$, and jumps to point 
F of steady flow characteristic to point $A$ as well as point B through the compressor maximum pressure rise coefficient, and the surge cycle repeats. However, the stability of the point of the intersection between $\Psi_{\mathrm{C}}(\Phi)$ and $\Psi_{\mathrm{T}}(\Phi)$ has been the topic of numerous studies [16-18], due to its importance in the safe, high performance operation of the axial flow compressor operations.

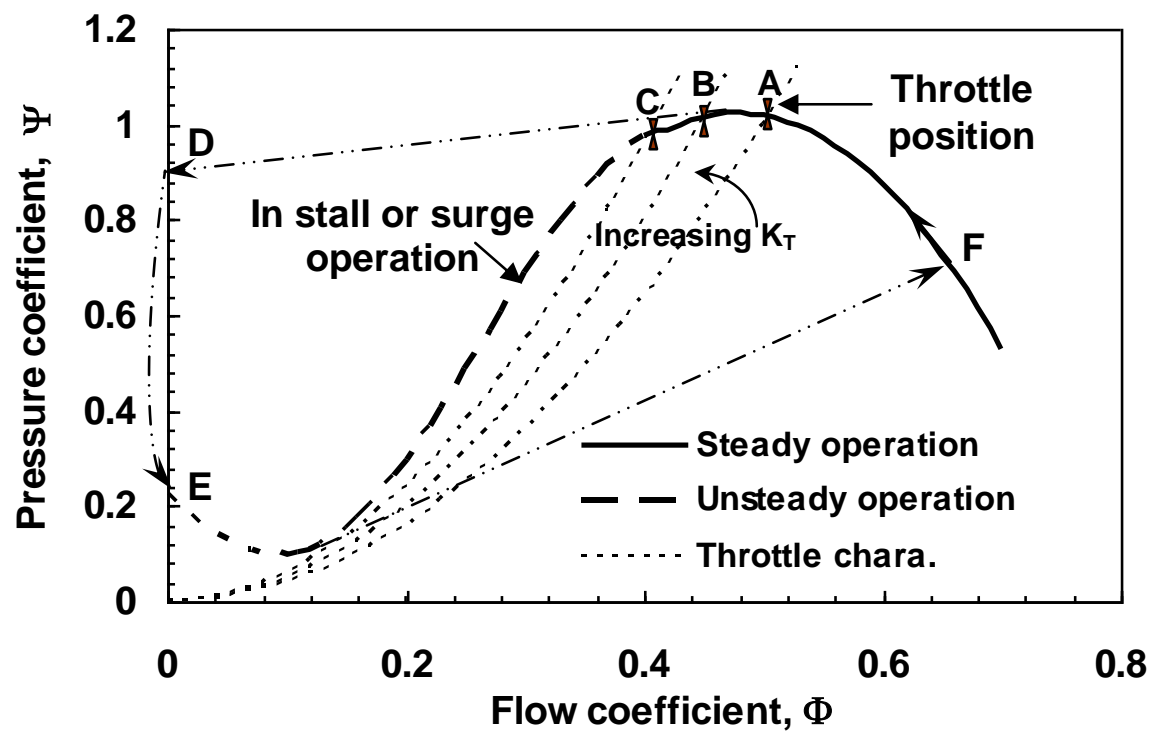

Fig. 3: Compressor and throttle behavior during stable and unstable operations.

\subsection{Compression System Model Using Mechanical Compensated System}

The aim of the present work is to increase steady operation zone of the axial flow compressor by using mechanical compensation system, Fig. 4. This mechanically compensated system is essentially constructed from a vibratory plenum wall and injection air through reed valve. In addition, air will be injected through a reed valve that is operated by a cantilever which is linked to a damper system. This reed valve works under effect of the pressure perturbations of the flow upstream the axial flow compressor on the cantilever that moves these perturbations to the damper system.

Influence of the controller on the axial flow compression system stability is described as follows: The first effect is the movable wall that has a surface area $A_{w}$. This surface is a part of spring-damper system responding to the unsteady plenum pressure perturbation, with a displacement $y$ that is proportional to the driving force. The change in plenum volume is $y A_{w}$ and the plenum mass change is $\rho y A_{w}$. The movable wall balancing equation in one direction is:

$$
M \ddot{y}+D \dot{y}+K y=\left(A_{w}+C\right) \Delta P_{p}
$$




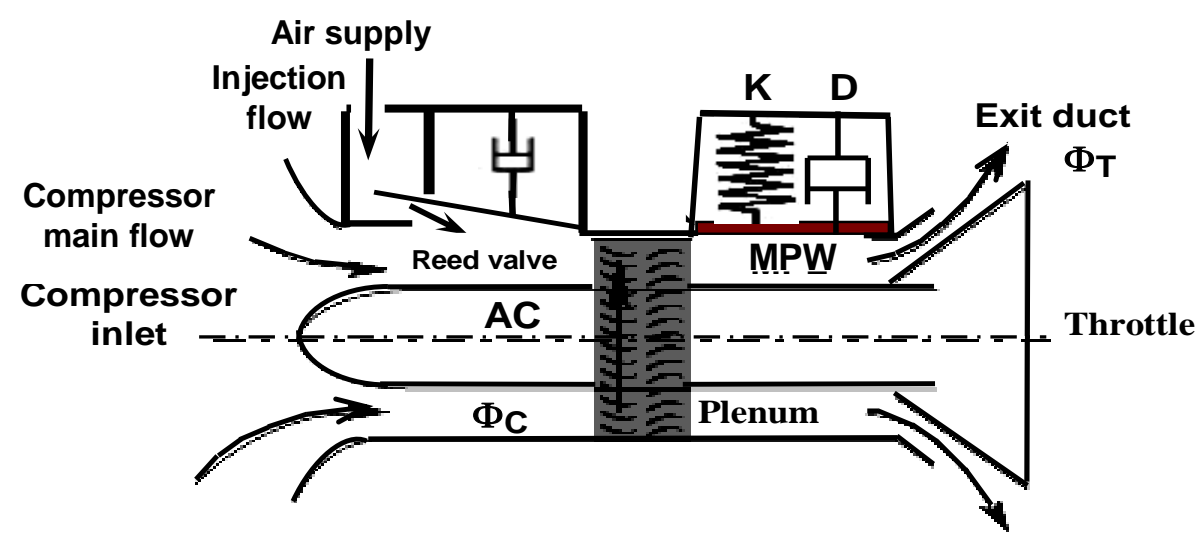

Fig. 4: Axial flow compressor of a movable plenum wall.

The second effect is injection using reed valve that responds to static pressure perturbations in the upstream flow field. This reed valve is modeled in a first cantilevered bending mode as single degree of freedom, mass-spring-damper system. The control force is generated by a feedback system that processes the signal detected by a pressure sensor located at compressor exit or in the plenum. The nondimensional, second order equation that describes the reed valve dynamics is:

$$
\ddot{q}+2 Q \zeta \dot{q}+Q^{2} q=G \Delta P_{p} / 6
$$

where, $q$ is the nondimensional reed valve opening ( $q=\delta / J, \delta$ is the reed valve opening and $J$ is the annulus height) and $Q$ is the natural frequency of the reed valve normalized by rotor frequency $\left(Q=\omega_{H} r / U\right)$. However, Greitzer and Moore [3] concluded that the compression system could inter in surge if the system B-parameter was greater than a critical B-parameter. Operation of a system with the B-parameter less than the critical B-parameter leads to the development of rotating stall instabilities rather than surge. Whereas, in fact the stability of the compression system must depend on both the throttle coefficient $\mathrm{K}_{\mathrm{T}}$ and the Greitzer B-parameter. For larger values of the throttle coefficient $\mathrm{K}_{\mathrm{T}}$ these axisymmetric solutions are stable, denoted with a solid line on Fig. 3. However, similar to Eq.(14) the compression system model with the movable plenum wall can be written as:

$$
\begin{gathered}
\frac{d \Phi_{c}}{d \tau}=B\left[\Psi_{c}\left(\Phi_{c}\right)-\Psi_{p}\right]-\mu \Phi_{c}-G \Psi_{c}\left(\Phi_{c}\right) \\
\frac{d \Psi_{p}}{d \tau}=\frac{1}{B}\left(\Phi_{c}-\Phi_{T}\right)-(F+H)\left(\frac{d \Psi_{p}}{d \tau}+f \Psi_{p}\right) \\
\frac{d \Phi_{T}}{d \tau}=\lambda B\left[\Psi_{p}-\Psi_{T}\left(\Phi_{T}\right)\right]-\zeta G \Psi_{c}\left(\Phi_{c}\right) \\
\frac{d \Psi_{c}\left(\Phi_{c}\right)}{d \tau}=\frac{1}{\tau}\left[\Psi_{o}-\Psi_{c}\left(\Phi_{c}\right)-h \Psi_{p}\right]
\end{gathered}
$$


where, $G=\rho l r^{2} / 6 m,(l$ is the length of reed valve normalized by annulus height and $m$ is the model mass of reed valve), $\zeta=b /\left(2 m \omega_{n}\right),(b$ is the reed valve damping constant, $\omega_{n}$ is natural frequency of the reed valve), $F=\left(\rho a^{2} A_{w}\right) /(y K)$, $H=\left(\rho a^{2} C\right) /(y K), f=K / D$ (spring stiffness/viscous damping coefficient) and $h$ is a constant depending on the throttle valve opening area. However, using the controller of a movable wall system of spring-damper four terms were added. The pressure-induced motion of the movable wall surface causes the term $f F \Psi_{p}$ that reduces the resonance frequency. While the compression system surge limit is increased by the control force term $f H \Psi_{p}$. The other terms, $\left(F d \Psi_{p} / d \tau\right)$ and ( $H d \Psi_{p} / d \tau$ ) are according to using spring. In respect of the reed valve, one term is added to the system $\zeta G \Psi_{c}$ that enhances the compressor surge limit.

The nonlinear perturbation equations for the quantities $\phi_{c}, \psi_{p}, \phi_{T}$ and $\psi_{c}$ from Eqs.(18) can be written in a matrix forms as:

$$
\left[\begin{array}{cccc}
s+\mu-(B-G) \psi_{c} & B & 0 & 0 \\
-1 / B & s(1+F+H)-f(F+H) & 1 / B & 0 \\
\zeta G \psi_{c} & -\lambda B & s+\lambda B \psi_{T} & 0 \\
\psi_{c} / \tau & h / \tau & 0 & s \Phi
\end{array}\right]\left[\begin{array}{l}
\phi_{c} \\
\psi_{p} \\
\phi_{T} \\
\psi_{c}
\end{array}\right]=\left[\begin{array}{l}
0 \\
0 \\
0 \\
0
\end{array}\right]
$$

To determine the effects of the control parameters on stability or surge margin , the reed valve dynamics were taken similar to Gysling and Greitzer [4] as $\mathrm{G}=3.5, \mathrm{Q}=$ $1.5, \zeta=0.3$ to 3 . Also, the values of the coefficients of $\mu, B, F, H, f, \lambda, \psi_{T}, \mathrm{~h}$, $\Phi, \tau$, are assumed as $0.02,1.28,0.9,0.9,0.6,120,900,1.32,0.03,0.48,50.3 t$ respectively. However, the fixed wall behavior is obtained in the limit of $F=-H$. Equation (19) reduces to the characteristic equation:

$$
s^{4}+a_{3} s^{3}+a_{2} s^{2}+a_{1} s+a_{o}=0
$$

Substituting the above values of the constants, the coefficients, $a_{3}, a_{2}, a_{1}, a_{o}$ can be determined and using the Mat lab to solve Eq.(20) to determine the values of the complex growth rate, $s$ can be determined using the Mat lab program. Then Eq.(19) can be solved to determine the system limit of stability. The throttle and compressor characteristic curves in steady state operation were taken corresponding to Greitzer [17]. However, the limit of stabilization for a given value of B-parameter, using the controller will occur at a point of the compressor characteristic where the slope $(d \Psi / d \Phi)$ is 1/B. This slope can be compared with that of natural surge point, that occurs at a value of $(d \Psi / d \Phi)$ given by substituting $d \Psi / d \Phi=\left(B^{2} \partial \Psi_{T} / \partial \Phi_{T}\right)^{-1}$, or for a parabolic throttle curve, $d \Psi / d \Phi=\Phi / 2 B^{2} \Psi$. On the other hand, Eq.(20) constitutes an eigenvalue problem for complex growth rate, $s$, solving the eigenvalue 
problem as a function of the marginal natural frequency and the mean flow coefficient using the experimentally determined compressor characteristic curves of Greitzer [17] enables prediction of the compressor instability onset condition for various system and control parameters. Therefore, similar procedures were carried out for the system without controller to determine the surge limit.

Figures 5 and 6 show the effects of the controller on the compressor characteristics, stability limit with the uncontrolled system (Fig. 5) of Greitzer [17] in which the compression system of the hard plenum walls and the controlled plenum (Fig. 6) of a movable plenum wall at the same value of B-parameter of 1.28. It is clear in Fig. 5, that at the surge condition the flow reached to zero flow rate or reversed flow may occur and a very large surge cycles were shown in this figure from the experimental and theoretical model of Greitzer[17]. Figure 6 shows a large surge cycle in case of the present model without controller at flow coefficient of 0.48 similar to that with Greitzer (Fig. 5). This figure shows effect of controller on the very large surge cycle becomes very small or eliminated at the same test conditions of $\mathrm{B}=1.28$ and flow rate of $\Phi=0.48$. Figure 6 also shows surge cycle with the controlled system but at low flow coefficient of 0.32 . That is the surge point moved from $\Phi=0.48$ to 0.32 results of system controller. Those figures concluded that the controller has moved the surge boundary notably toward the left system stability enhancement by about $24 \%$.

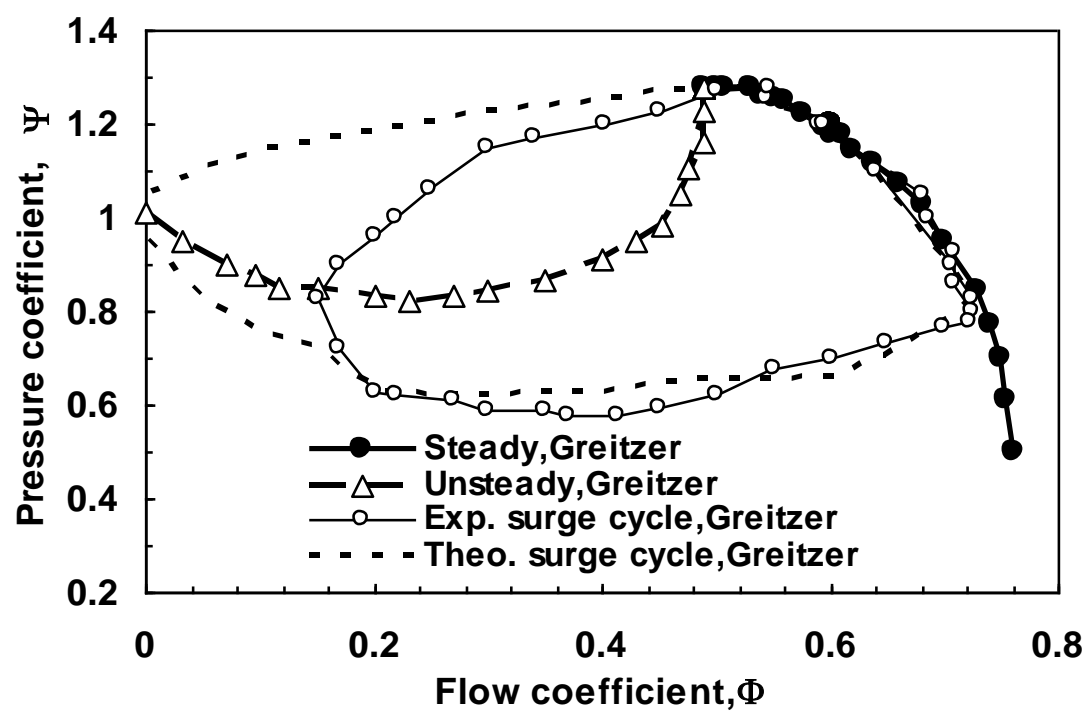

Fig. 5: The compression system without controller, Greitzer [17],B=1.27 .

Effects of B-parameter on the fluctuations of pressure and flow coefficients are shown in Fig. 7. This figure shows that increasing the value of B-parameter increases both the amplitudes of pressure and flow fluctuations. The controller decreases the fluctuation of pressure by about $27 \%$ and mass flow fluctuations about $40 \%$. This figure shows good comparisons between the experimental and theoretical 
results of Greitzer [17] and with the present theoretical results without controller. However, effect of B-parameter on the compression system stability can be explained as follows; at large B-parameter, the pressure forces dominate over the inertia forces and produce a driving force for the acceleration of the fluid in the system. Therefore, global oscillations, in this context referred to as surge, grow stronger and destabilize the system. On the contrary, in systems with small B-parameters, the inertia forces dominate over the pressure forces and cause the oscillations to decay. Therefore, the control effectiveness decreases as either or both B-parameter and the slope of the compressor characteristic increase.

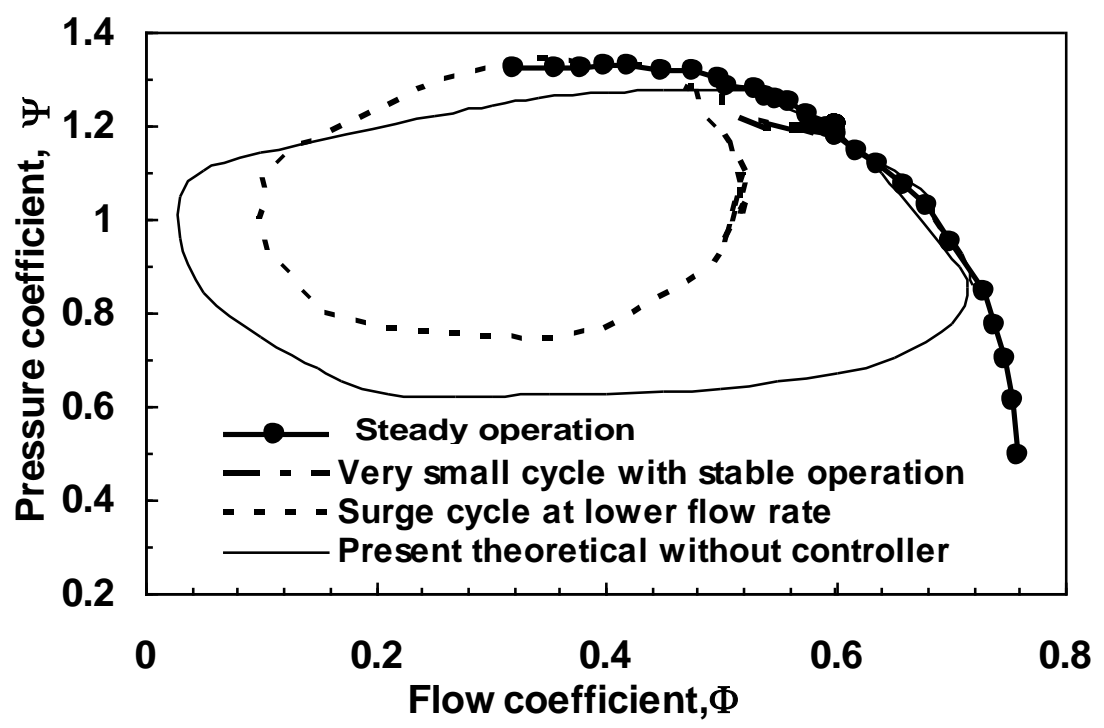

Fig. 6: The compression system with and without controller, $B=1.27$.
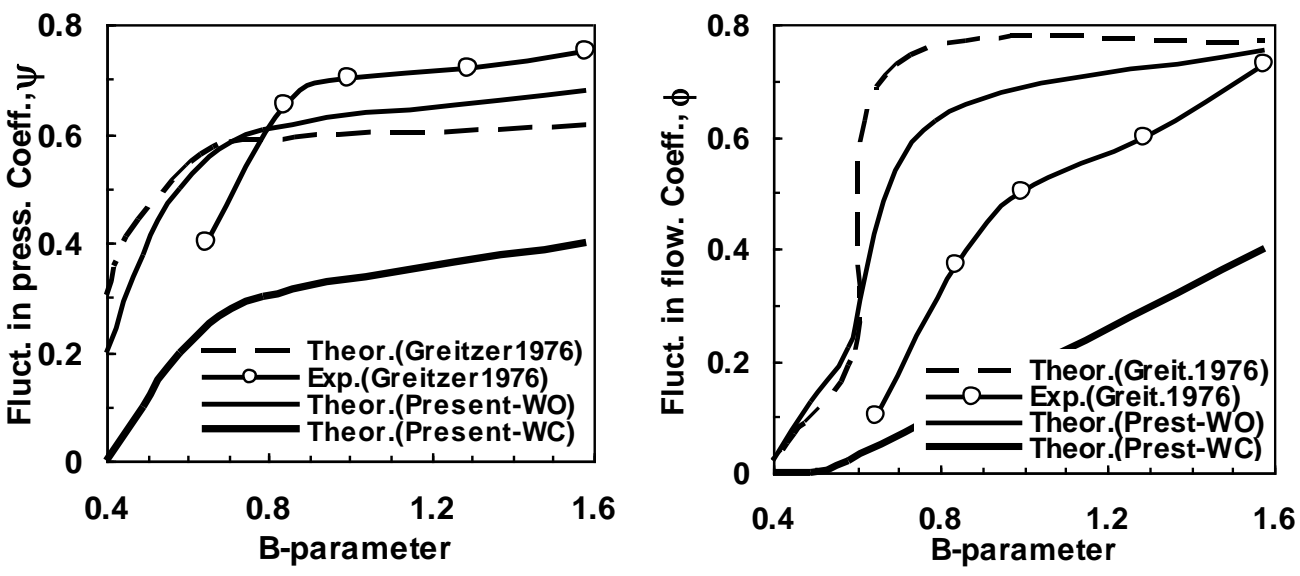

Fig. 7: Effect of controller on fluctuation of pressure and flow coefficients.

(WO = without controller and WC= with controller) 
The physical reason for the decreased effectiveness of the controller with increase in B-parameter is related to the overall decrease in stability that occurs as B-parameter increases. That is because large B-parameter implies a more throttle is less coupled to the unsteady flow through the axial flow compressor.

\section{EXTENDED MODELS FOR ROTATING STALL AND SURGE CONTROL}

\subsection{Bifurcation Analysis of Extended Moore Greitzer Model}

The target of this part in the present work is extending the Moore-Greitzer model [3] for increasing the axial flow compressor range of stable operation using bifurcation analysis. The three nonlinear ordinary differential equations of the model arise from a Galerkin approximation of the local momentum balance, the annulus averaged momentum balance and the mass balance of the plenum, are written similar to McCaughan [7], Chatururvedi and Bhat [19] as follows:

$$
\begin{aligned}
& \dot{\Phi}_{c}(\tau)=-\Psi_{p}(\tau)+\Psi_{c}\left(\Phi_{c}(\tau)\right)-3 \Phi_{c}(\tau) R(\tau) \\
& \dot{\Psi}_{c}(\tau)=\left[\Phi_{c}(\tau)-\Phi_{T}(\Psi(\tau))\right] / B^{2} \\
& \dot{R}(\tau)=\sigma R(\tau)\left[1-\Phi_{c}^{2}(\tau)-R(\tau)\right]
\end{aligned}
$$

where, $\dot{R}$ is the differentiation in respect to time of the square of the normalized rotating stall perturbations amplitude and $\sigma$ is a nondimensionalized parameter that depends on the compressor geometry and the shape of the compressor characteristic. The equilibrium mass flow is controlled by opening and closing the throttle, i.e., by increasing and decreasing $h$. The general form of the throttle $\left(\Phi_{T}\right)$ and the compressor $\Psi_{c}\left(\Phi_{c}\right)$ characteristics in steady axisymmetric flow respectively can be written as:

$$
\begin{aligned}
& \Psi_{T}(\Phi)=\sqrt{h \Psi_{p}}-1 \\
& \Psi_{c}\left(\Phi_{c}\right)=\Psi_{c o}+1+1.5 \Phi_{c}-0.5 \Phi_{c}{ }^{3}
\end{aligned}
$$

where $h$ is the throttle nondimensionalized parameter that proportional to the throttle valve area (control). Setting the dot quantities in Eq.(21) to zero and taking the compressor shutoff coefficient, $\Psi_{c o}=1.3, B=0.71, R \geq 0$ and $\sigma=7$. Thus, Eq.(21) represent possible steady state operating points of the compressor. A focus on Eq.(21-c) reveals two possibilities: axisymmetric equilibrium solution with $R=0$ or non-axisymmetric rotating stall equilibria with $R=1-\Phi_{e}^{2}$. From Eq.(21-a), the pressure rise for axisymmetric equilibrium solutions is $\Psi=\Psi_{c}$, which is the cubic compressor characteristic defined in Eq.(23). The pressure rise $\Psi_{r}(\Phi)$ for rotating stall equilibria solutions, called the rotating stall characteristics is:

$$
\Psi_{r}=\Psi_{c}\left(\Phi_{c}\right)-3 \Phi_{c}\left(1-\Phi_{c}^{2}\right)=\Psi_{c o}+1-1.5 \Phi_{c}+2.5 \Phi_{c}^{3}
$$


For each equilibrium value of the mass flow coefficient $\left(\Phi_{e}=\Phi_{c}\right)$, the compressor can operate at an axisymmetric equilibrium for $\Phi_{e} \geq 1$, given by $\left(\Phi_{e}, \Psi_{e}, R_{e}\right)$ $=\left(\Phi_{e}, \Psi_{e}\left(\Phi_{e}\right), 0\right)$ or at rotating stall equilibrium for $\left|\Phi_{e}\right|<1$, that given by $\left(\Phi_{e}, \Psi_{e}, R_{e}\right)=\left(\Phi_{e}, \Psi_{s}\left(\Phi_{e}\right), 1-\Phi_{e}^{2}\right)$, where $\Psi_{s}(\Phi) \equiv \Psi_{c}(\Phi)-3 \Phi\left(1-\Phi^{2}\right)$ is the rotating stall compressor characteristic. The value of throttle parameter needed to maintain operation at the equilibrium mass flow $\Phi_{e}$ can be obtained from Eq.(22) as: $h_{e}=\left(1+\Phi_{e}\right) / \sqrt{\Psi_{e}}$. On the other hand, at the axisymmetric operating point ( $\Phi_{c}=\Phi_{e}$, denoted as $\left.x_{o 1}\right)$, Eq.(21) has a steady solution with $R_{e}=0$, where $x_{o 1}=\left(\Phi_{e}, \Psi_{e}, 0\right), \Phi_{e}=\Phi_{T}\left(\Psi_{e}\right), \Psi_{e}=\Psi_{c}\left(\Phi_{e}\right)$. The Jacobian derivative of Eq.(21) can be written as:

$$
\left(\begin{array}{ccc}
\dot{\Psi}_{c}\left(\Phi_{e}\right)-3 R_{e} & -1 & -3 \Phi_{e} \\
1 / B^{2} & -\dot{\Phi}_{T}\left(\Psi_{e}\right) / B^{2} & 0 \\
-2 \sigma \Phi_{e} R_{e} & 0 & \sigma\left(1-\Phi_{e}^{2}-2 R_{e}\right)
\end{array}\right)
$$

Substituting $x_{o 1}$ in the Jacobian derivative (Eq. (25)), the associated eigenvalues can be calculated. At fully open throttle, the eigenvalues all have negative real part and the steady axisymmetric flow is stable. The first eigenvalue to become positive is: $\lambda_{1}=\sigma\left(1-\Phi_{e}^{2}\right)$, where $\lambda_{1}$ is the eigenvalue of Jacobian derivative. At the critical flow rate (throttle setting $h=h_{c}$ or $\Phi_{e}=1, \lambda_{1}=0$ ), the associated eigenvector is $\left(\Phi_{e}, \Psi_{e}, 1\right)$ pointing up out of the $R=$ zero plane. Closing the throttle further results in loss of stability of $x_{o 1}$. If the throttle is closed more to a point where the real part of the complex pair of eigenvalues is zero (a Hopf bifurcation point). At this operating condition, the Jacobian derivative reduces to;

$$
\left(\begin{array}{cc}
\dot{\Psi}_{c}\left(\Phi_{e}\right) & -1 \\
1 / B^{2} & -\dot{\Phi}_{T}\left(\Psi_{e}\right) / B^{2}
\end{array}\right)
$$

This matrix has a purely imaginary pair of eigenvalues when its trace is zero which follows; $B^{2}=\dot{\Phi}_{T}\left(\Psi_{e}\right) / \Psi_{c}\left(\Phi_{e}\right)$ which is shown in Fig. 8. This figure shows that decreasing $h$ corresponding to reducing the compressor flow coefficient reduces system stability. When $h<h_{c}$, the fixed point is stable to all perturbations and under the curve it is axisymmetric stable. This figure shows also that as the shutoff head coefficient of the compressor, $\Psi_{c o}$ decreases the compressor limit of stability decreases, due to increase in throttle slope. Because the slope of the compressor characteristic is equal to1/B at maximum gain therefore, the instability occurs when the slopes of the compressor and throttle lines are equal. That is the limit of stabilization will occur at a point on the compressor characteristic where the slope 
( $d \Psi / d \Phi)$ is $1 / \mathrm{B}$. This slope can be compared with that for natural surge point, which occurs at value of $d \Psi / d \Phi=1 /\left[B^{2}\left(\partial \Psi_{T} / \partial \Phi\right)_{T}\right]=\Phi / 2 B^{2} \Psi$. This means that the control effectiveness as either or both the slope of the compressor characteristic and Bparameter increase. This conclusion agrees well with results of Gysling and Greitzer [4].

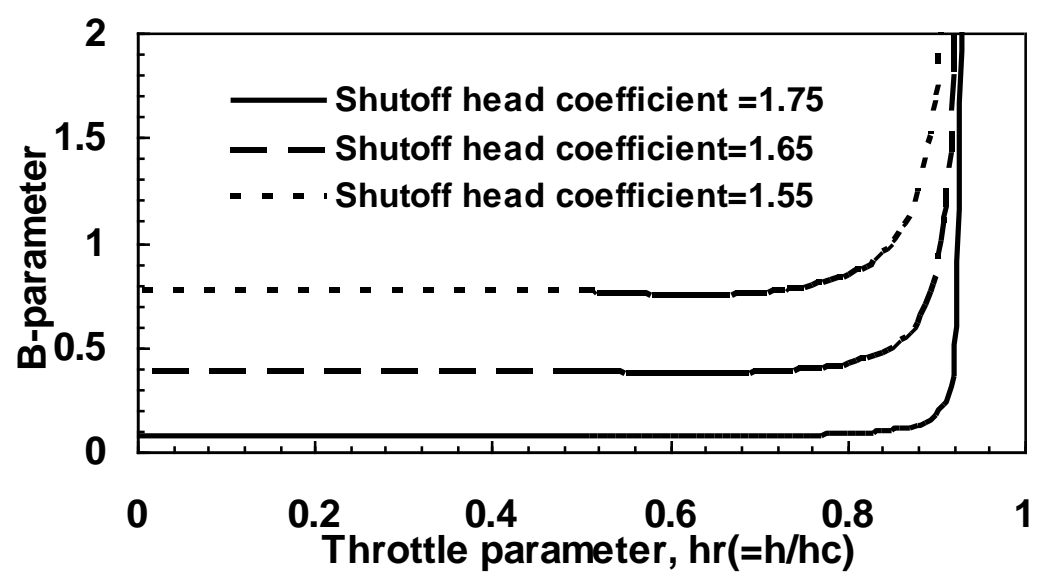

Fig. 8: Effect of shutoff head coefficient, $\Psi_{c o}$ on compressor stable operation.

\subsection{Compressor Instability Elimination by Modifying the Throttle Characteristic}

Back to Fig. 3, operating the compressor at the critical flow condition of instability ( $h=h_{c}$ ), the system makes transition (jump) to rotating stall or surge rather than the axisymmetric depending on the throttle characteristic and B-parameter. Limit cycles from Hopf bifurcations in $R=0$ plane cause deep surge. As the flow rate decreases, the surge cycles lose stability at a fold bifurcation, and the system jumps to the rotating stall equilibria solution. Thus, there are two ways hysteresis between steady axisymmetric flow, surge and rotating stall.

The aim of this part in the present work is to eliminate the hysteresis loop associated with steady axisymmetric flow and avoids instabilities using a nonlinear feed back control law. As discussed above the hysteresis occurs due to jump at different values of $h$ or depends on the throttle characteristic. This means that hysteresis in compressor characteristic can be eliminated by modifying the throttle characteristic such that the jumps do not occur. Therefore, doing throttle characteristic cut the instability (hysteresis) at the maximum pressure coefficient point, makes the bifurcation supercritical leads operating point will vary smoothly from instability characteristic and vice versa. However, it is clear in Fig. 3 and according to Equ. (24), that the stability of the compression systems dependent on the throttle coefficient, therefore the bifurcation solution at $h=h_{c}$ can be written as $h=h(R)$. However, the maximum value of $h(R)$ occurs at $R>0$ and is responsible for jump between the rotating stall and axisymmetric equilibrium characteristics. Then this jump can be 
avoided if $h(R)$ is made to occur at $R=0$. Therefore, Gupta and Ananthkrishanan [25] made such control law, given by

$$
h=\left(\sqrt{h_{o}}+K_{1} / \sqrt{\Psi_{p}}\right)^{2}
$$

where $h_{o}$ is the new nominal value of the throttle position, $K_{1}$ is the gain which will eliminate the hysteresis between the steady axisymmetric flow and rotating stall. To increase the compressor limit of stability, substituting the modified throttle characteristic, $\Phi_{T}=\sqrt{h_{o} \Psi_{p}}+K_{1}-1$ ), into Equ. (15-b) which becomes:

$$
\frac{d \Psi_{p}}{d \tau}=\frac{1}{B^{2}}\left(\Phi_{c}-\sqrt{h_{o} \Psi_{p}}+K_{1}-1\right)
$$

It must be mentioned here that the above assumption for modified throttle characteristics do not consider the compressor critical flow coefficient or equilibrium points. Adding those parameters to the throttle coefficient, Equ.(28) becomes:

$$
\frac{d \Psi_{p}}{d \tau}=\frac{1}{B^{2}}\left(\Phi_{c}-\sqrt{h_{o} \Psi_{p}}+1-K_{1}\left(1+\Phi_{e}\right)\right.
$$

However, solving of the modified system for the equilibrium values, to determine the value of $K_{1}$ the following expression were found for the throttle coefficient, $h_{o}$

$$
h_{o}=\frac{\left[\Phi_{e}\left(1-K_{1}\right)-K_{1}+1\right]^{2}}{\Psi_{e}}=\frac{\left[\Phi_{e}\left(1-K_{1}\right)-K_{1}+1\right]^{2}}{\Psi_{c o}-1.5 \Phi_{e}+2.5 \Phi_{e}^{3}+1}
$$

To eliminate the compressor instability (hysteresis), maximum value of $h_{o}(R)$ must occur at $R=0$, i.e. $d h_{o} /\left.d R_{e}\right|_{R_{e=0}}=0$. The variation of throttle coefficient in relative to instability perturbations amplitude can be written as:

$$
d h_{o} / d R_{e}=\left(d h_{o} / d \Phi_{e}\right)\left(d \Phi_{e} / d R_{e}\right)
$$

At the equilibrium condition, $R_{e}=0$ and $\Phi_{e}=1$, then, $d \Phi_{e} / d R_{e}=-0.5 / \Phi_{e}$, hence

$$
d h_{o} / d \Phi_{e}=\left\{2 \Psi_{e}\left[\left(\Phi_{e}\left(1-K_{1}\right)-K_{1}+1\right]-\left[\left(\Phi_{e}\left(1-K_{1}\right)-K_{1}+1\right]^{2}\left(-1.5+7.5 \Phi_{e}^{2}\right)\right)\right\} / \Psi_{e}^{2}\right.
$$

Solving for Equ.(31) at $d h_{o} / d R_{e}=0$ with $\Phi_{e}=1$ and $\Psi_{c o}=1.02$ the value of $K_{1}$ could be evaluated. Accordingly, in order to increase the limit of stability of Paduano et al.[5] axial flow compressor, relative to his experimental work, the value of $K_{1}$ should lie between 0.67 and 1.35. Figure 9 shows effect of throttle gain $K_{1}$ on the instability perturbations amplitudes, $R$ versus the throttle coefficient, $h_{O}$. The solid lines are for stable operation while the dotted lines represent unstable regions. The area between the two arrows in the figure indicates the unstable operation section. The left arrow is at the critical throttle valve opening $\left(h=h_{c}\right)$ that corresponds to the peak of the compressor characteristic, $\partial \Psi_{c} / \partial \Phi=0$. This figure suggests a hysteresis 
region as the throttle is closed $R=0$ is a stable solution until $h=h_{c}$, at which point the stable solution for $R \neq 0$ which corresponds to a jump to unsteady flow of rotating stall or surge. As the throttle opening area $(h)$ continues to decrease, the stable solution for $R$ continues to be non-zero. If the throttle is then opened, beginning at $h<h_{c}$, the system continues to involve along the unsteady branch until $h$ is increased to a value substantially greater than $h_{c}$ before returning to the $R=0$ branch. That is, the system has substantially different solutions depending on the path that the throttle valve opening follows. However, in Fig. 9 the area between the two areas are for unsteady operation. That is decreasing the value of the throttle gain $K_{1}$ decrease the instability and the suitable range of the throttle gain $K_{1}$ should lay between 0.67 and 1.35 at values of throttle area less than or equal to 0.67 . According to the results in Fig. 9 the hysteresis may occur at $h<h_{c}$ without controller $\left(K_{1}=0\right)$, at throttle opening, $h=0.67-0.78$. That is, this controller cannot eliminate the surge while could be controlled rotating stall only. Therefore, another controller should be making to control the surge. The suggested controller is to modify the throttle control low (adding anther throttle gain $K_{2}$ beside $K_{1}$ ) to become:

$$
h=K_{2}^{-2}\left\{\sqrt{h_{o}}+\Psi_{p}^{-0.5}\left[K_{1}+(1+\Phi)\left(K_{2}-1\right)\right]\right\}^{2}
$$

Substituting Equ.(33) into Equ.(21b) gives:

$$
\dot{\Psi}_{c}=\left(1+\Phi_{c}-K_{1}-\sqrt{h_{o}} \Psi_{c}\right) /\left(K_{2} B^{2}\right)
$$

Equation (34) shows that the controller gain $K_{2}$ can be used to degree the value of Bparameter. In this case the throttle gains $K_{1}$ and $K_{2}$ can be selected as $K_{1}=0.67$ and $K_{2}=0.1-0.05$. Figure 10 shows effect of the throttle gains on compressor stability or so-called bifurcation diagram. It is clear in the figure that there is no hysteresis or Hopf bifurcation point. At value of $K_{1}=0.67$ and $K_{2}=0.1$ very small perturbation was

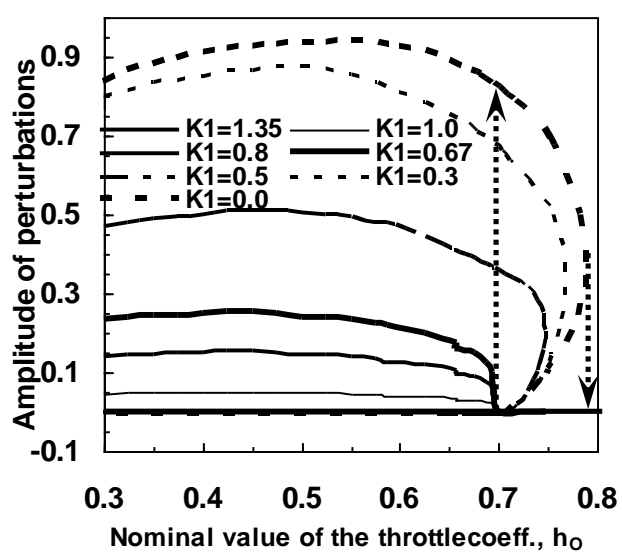

Fig. 9: Effect of throttle gain, K1.

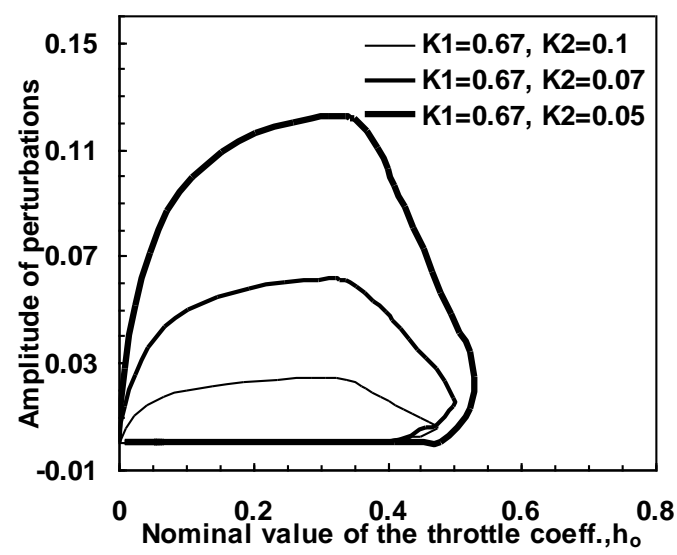

Fig. 10: Effect of throttle gain, K1. 
shown while at $K_{1}=0.67$ and $K_{2}=0.05$ the gain does not reaches the critical limit of 0.67 . That is the surge is eliminated or suppressed by this controller.

\subsection{Control of Stall and Surge Using Air Injection}

According to the experimental results of Behnken et al., [26] the air injection actuators improved the compressor performance characteristic. The target in this par of the present work is to apply this idea of air injection (increase the angular momentum) into the present model hoping to increase the compressor performance. In order to control the aerodynamic instability, the air injection actuators is considered as direct actuators of the steady state compressor characteristic and the feedback is to proportional to instability perturbations amplitudes $(R)$. Then, the compressor characteristic with air injection, $\Psi_{c i}\left(\Phi_{c}\right)$ is:

$$
\Psi_{c i}\left(\Phi_{c}\right)=\Psi_{c}\left(\Phi_{c}\right)+K_{2} R \Psi_{c a}
$$

where, $\Psi_{c a}=e_{o}+e_{1} \Phi_{c}, e_{o}$ and $e_{1}$ are coefficient used to fit the experimental data of [26]. Since, the aim of this part of the preset work is to shift the steady state compressor characteristic that proportional to $R$, the slope of the bifurcation curve must be solved at operating point of critical throttle position $\left(h_{c}\right)$. Therefore, at the unsteady branch (stall and surge) of bifurcation diagram the following algebraic equation must be hold:

$$
\begin{aligned}
& \Phi_{T}=\left(h+K_{1} \Phi_{T}\right) \Psi_{T}^{0.5} \\
& \Psi_{c}\left(\Phi_{c}\right)=\Psi_{p}-0.25 R \partial^{2}\left[\Psi_{c i}\left(\Phi_{c}\right)\right] / \partial \Phi_{c}^{2} \\
& \partial\left[\Psi_{c i}\left(\Phi_{c}\right)\right] / \partial \Phi_{c}=-0.125 R \partial^{3}\left[\Psi_{c i}\left(\Phi_{c}\right)\right] / \partial^{3} \Phi_{c}
\end{aligned}
$$

Differentiating Eq.36 in respect to $R$ at the peak of the compressor characteristic and substituted the differentiation of Equ.(36b) and (36c) into differentiation of Eq.(36a). By solving the result of the last algebraic configuration for $d R / d h$, Then the slope of the bifurcation diagram at the critical compressor operating point $\left(h_{c}\right)$ is:

$$
\left.\frac{d R}{d h}\right|_{h=h_{c}}=\frac{\sqrt{\Psi_{p}}}{\frac{K_{2} \partial \Psi_{c a} / \partial \Phi_{c}+0.125 \partial^{3} \Psi_{c} / \partial \Phi_{c}^{3}}{\partial^{2} \Psi_{c} / \partial \Phi_{c}^{2}}-\frac{\Phi_{c}}{2 \Psi_{T}}\left(K_{2} \Psi_{c a}+0.25 \partial^{2} \Psi_{c} / \partial \Phi_{c}^{2}\right)}
$$

Equation (37) shows that varying the throttle gain effects on the compressor characteristic and the slope of the bifurcation diagram at the critical throttle opening. Figure 11 shows the effect of using air injection on the compressor performance characteristic. Figure 11a represents the present model using the injection airflow as a control feed back effects on bifurcation curve. While Fig.11b shows the experimental results of Behnken [26]. The dashed line in Fig. 11b results of the system without air injection and the solid line for the continuous air injection. Figure11 shows the air injection as feed back control of instabilities phenomena might be increase not only the range of stable operation of the compressor but also the its pressure coefficient. Comparison of the present model results in Fig.11a and the experimental results of 
Behnken [26] shows an acceptable agreement in trend of effect of controller on compressor performance. Therefore, the result concluded that using the air injection causes two benefits to the axial flow compressor those are increasing the pressure coefficient at which unsteady rotating stall and surge occurs and range of stable operation.

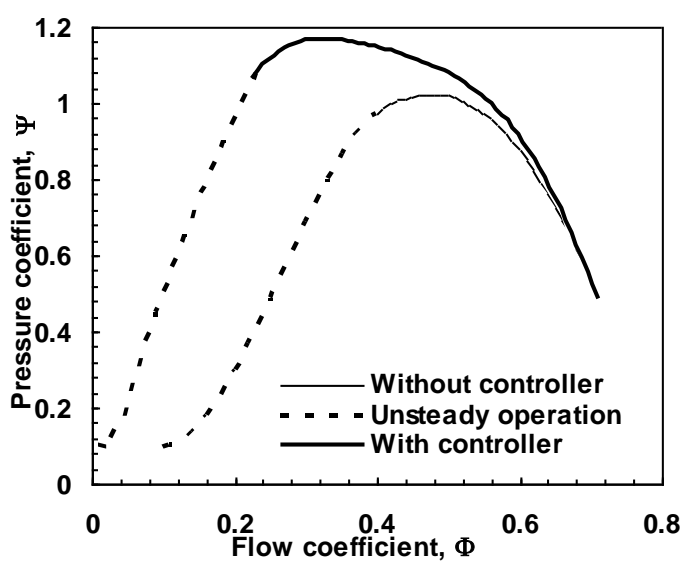

(a) Present model

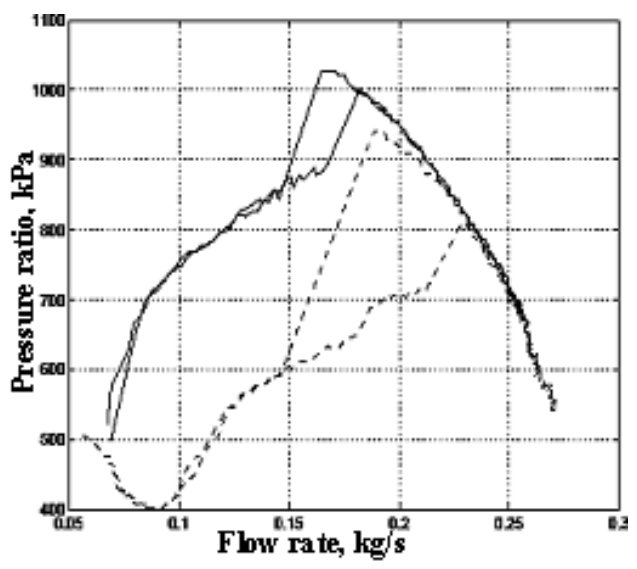

(b) Experimental work of Behnken [26]

Fig. 11: Compressor performance with and without controller using air injection.

\section{CONCLUSIONS}

Rotating stalls initiations and limits in the axial flow compressors were investigated using a simple model that considers transport of energy by the rotor wakes passing through the stator and the pressure losses through the compressor. Active suppression of the aerodynamic instabilities in the axial flow compressors were demonstrated using mechanical compensated system with controlled plenum simultaneously with air injection through reed valve. The reed valve, which was modeled as mass-spring-damper, regulated the amount of air injected into the face of the axial flow compressor. The bifurcation analysis was performed to determine the effect of throttle gain on the compressor limit of stability and then modifying the throttle characteristic to eliminate hysteresis and suppresses surge. The Moore and Greitzer model was extended to include the effects of air injection on the compressor performance characteristic and to increase the limit of stability. The results show that:

1. The rotor and the stator wakes are the main cause of rotating stall initiations.

2. The vibratory plenum wall together with the injection through the reed valve damps the amplitude of the pressure and flow pulsations and increases the limit of stability by about $24 \%$.

3. Modifying the throttle gain and characteristic eliminates the hysteresis and suppressed the surge in the axial flow compressors. 
4. The air injection eliminated the hysteresis loop associated with the unsteady flow of rotating stall and surge and improved the compressor performance characteristics.

\section{REFERENCES}

[1] Nelson, E., Paduano, J. and Epstein, A., "Active Stabilization of Surge in an Axial Centrifugal Turbo shaft Engine", ASME J. of Turbomachinery, Vol. 122, pp. 485-493, 2000.

[2] Jan, T., Olav, E. and Svein, V., "Drive Torque Actuation in Active Surge Control of Centrifugal Compressors", Automatica, Vol. 38, No. 11, 2002.

[3] Moore, F. and Greitzer, E., "A theory of Post-Stall Transients in Axial Compression Systems", ASME, J. of Eng. for Gas Turbine and Power, Vol.108, 68-76, Jan.1986.

[4] Gysling D. and Greitzer, E., "Dynamic Control of Rotating Stall in Axial Flow Compressors Using Aeromechanical Feedback", ASME, J. of Turbomachines, Vol. 117, pp. 307-319, 1995.

[5] Paduano, J.D. Mansoux, C.A., Gysling, D.L., and Setioawan J.D., "Active Control of Rotating Stall in a Low-Speed Axial Compressor" ASME J. of Turbomachinery, Vol. 115, pp. 48-56, Jan. 1993.

[6] Abed, E.H., Houpt, P.K. and Hosny, W.M., "Bifurcation Analysis of Surge and Rotating Stall in Axial Flow Compressors", Trans. ASME J. of Turbomachinery, Vol. 115, pp. 817-824, Oct. 1993.

[7] McCaughan, F. E., "Bifurcation Analysis of Axial Flow Compressor Stability", J. of Society for Ind. and Applied Math., Vol. 50, No. 5, pp. 1232-1253, Oct. 1990.

[8] Csaba, H. and Alan, C., "Bifurcation Analysis of Surge and Rotating Stall in the Moore-Greitzer Compression System”, kullmann@ vizgep.bme.hu, Sept. 2002.

[9] McCaughan, F.E., "Numerical Results for Axial Flow Compressor Instability", Trans. of the ASME, J. of Turbomachinery, Vol. 111, pp. 434 -441, Oct. 1989.

[10] Freeman, C. Wilson A. and Day, J., "Experiments Active Control Stall Aeroengine Gas Turbine”, ASME Turbo Expo, Orlando, GT-280, June 1997.

[11] Liao, S., "Robust Control of Surge and Rotating Stall in an Axial Compressor", Ph.D. dissertation, MIT, Cambridge, MA, 2000.

[12] Prasad, J. V., Neumeier, Y. and Krichene, A., "Active Control of Compressor Surge Using a Real Time Observer", Proc. of AVTC, Braunschweig, Germany, May 2000.

[13] Fontaine, D., Liao, S., Paduano, L. and Kokotovic, P., "Nonlinear Control Experiments On Axial Flow Compressor", IEEE, Trans. on Control Systems Technology, Vol. 12, No. 5, Sep. 2004.

[14] Hayami, H., Ahmed S. Hassan, Hiraishi, E., and Hasegawa, H. "Experimental investigation on stall and surge in centrifugal blower" Unsteady Aerodynamics and Aero elasticity of Turbomachines, pp. 727-736, Elsevier 1995.

[15] Kerrebrock, J. L. and Mikolajczak, A.A., "Intra-Stator Transport of Rotor Wake and its Effect on Compressor Performance", ASME, J. of Eng. for Power, pp. 359-368, October 1970. 
[16] Le, B. Y., Paulon, J. and Belaygue P., "Theoretical and Experimental Determination of Pressure Losses in a Single Stage Axial Flow Compressor", ASME, J. of Eng. for Power, pp. 359-368, October 1970.

[17] Greitzer, E. M., "Surge and Rotating Stall in Axial Flow Compressors", Part II: Experimental Results and Comparison with Theory, ASME, J. Engineering for Power Vol. 98, pp.199-217, April 1976.

[18] Mansoux, C. A., Gysling, J. D., Setioawan J. D. and Paduano, J.D., "Distributed Nonlinear Modeling and Stability Analysis of Axial Compressor Stall and Surge" In. Proc. American Control of Conference, pp. 2305-2316, 1994.

[19] Chaturvedi, N. A. and Bhat, S. P., "Output-Feedback Semiglobal Stabilization of Stall Dynamics for Preventing Hysteresis and Surge in Axial-Flow Compressors", IEEE Trans. on Control Systems Technology, Vol. 14, No. 2, March 2006.

[20] Abo El-Lail A.S. and Ahmed S. Hassan, "Active Suppression of Compressor Flow Instability" $8^{\text {th }}$ International Symposium on Unsteady Aerodynamics and Aero elasticity of Turbomachines, Stockholm, Sweden, pp. 495-509,14-18 Sep., 1997.

[21] Ffowcs, F.E., and Huang, X.Y., "Active Stabilization of Compressor Surge", ASME, J. of Fluid Mech., Vol. 204, pp.245-262, 1989.

[22] Abo El-Lail, A. S., Mohamed, H.A., and Abdel-Shafi, N.Y., "Mechanical Compensation System For Low Speed Centrifugal Blower", Bulletin of the Faculty of Eng. Assiut University, Vol. 29, No.2, May 2001.

[23] Paduano, J.D. Greitzer, E.M. and Epstein, A.H., "Compression system stability and active control”, Annu. Rev. Fluid Mech., Vol. 33, pp.491-517, 2001.

[24] Michael, H., William, H. and Kenneth, K .D., "Numerical Solution of Nonlinear $\mathrm{H}_{2}$ and $H_{\infty}$ Control Problems with Application to Jet Engine Compressors", IEEE, Trans. on Control Systems Technology, Vol. 8, No. 1, Sep. 2000.

[25] Gupta R. and Ananthkrishanan, N., "Survey of Stall/Surge Dynamics and Control Techniques in Axial Flow Compressors", J. of Aeronautical Society of India, 1999.

[26] Behnken, R.L., D'Andrea, R. and Murrray, R.M., "Control of Rotating Stall in a Low Speed Axial Flow Compressor Using Pulsed Air Injection: Modeling, Simulations and Experimental Validation", Proc. IEEE Control and Decision Conference, pp. 3056-3061, 1995.

[27] Protz, J. and Paduano, J., "Rotating Stall and Surge: Alternate Modeling and Control Concepts", IEEE Int. Conf. Control Applications, Hartford, CT, pp. 866873, Oct. 1997.

[28] Yeung, S. and Murray, R., "Theoretical Comparison of Nonaxisymmetric Air Injection Control of Rotating Stall on Axial Flow Compressors," Proc. Conf. Decision Control, Phoenix, AZ, vol. 4, pp. 3236-3241, 1999.

[29] Weigl, H., Paduano, J., Frechette, L., Epstein, A., and Greitzer, E., “Active Stabilization of Rotating Stall and Surge in a Transonic Single Stage Compressor," J. Turbomachinery, vol. 120, pp. 625-636, 1998.

[30] Protz, J., "Nonlinear Active Control of Rotating Stall and Surge," M.S. thesis, MIT, Cambridge, MA, 1995. 
[31] D'Andrea, R. Behnken, R., and R. Murray, "Active Control of an Axial Flow

Compressor via Pulsed Air Injection," J. Turbomachinery, vol. 119, no. 4, pp. 742-752, 1998.

\section{الإخماد النشيط لعدمِ الإستقرار الايناميكي الهوائي في ضواغطِ التدفي المحوريةِ}

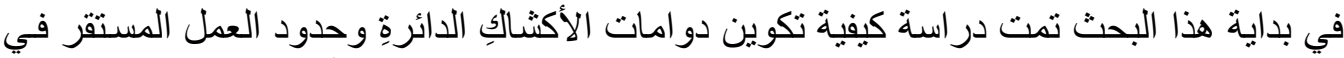

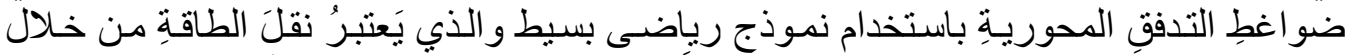

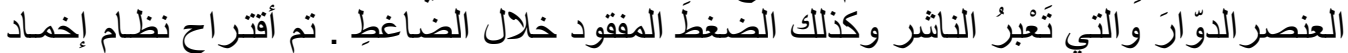

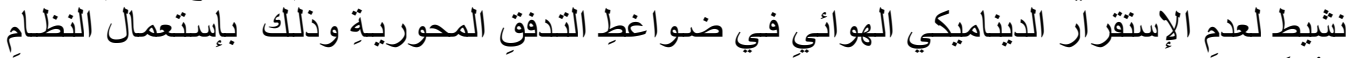

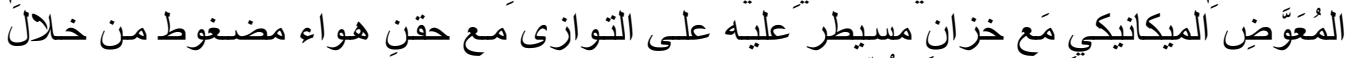

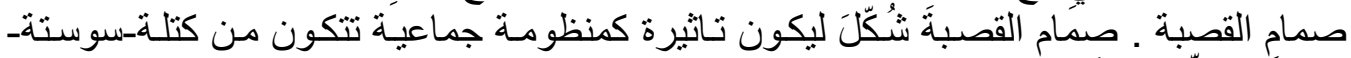

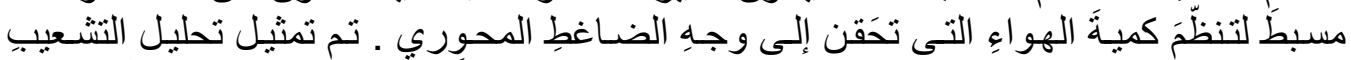

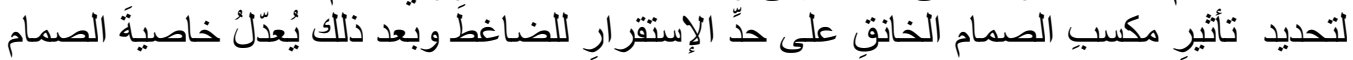

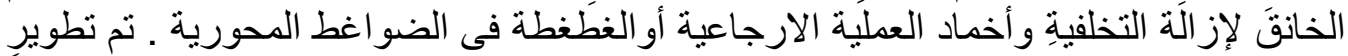

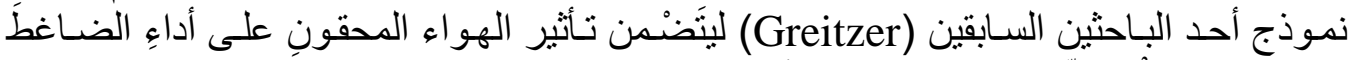

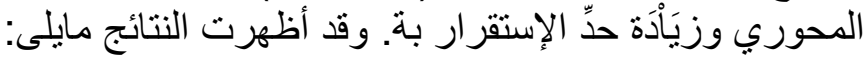

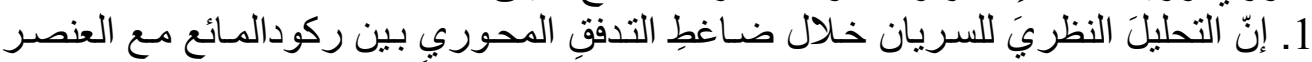

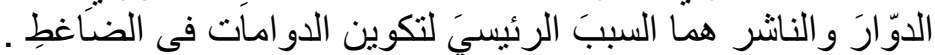

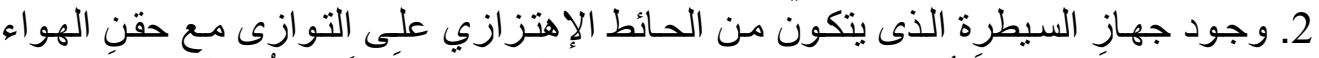

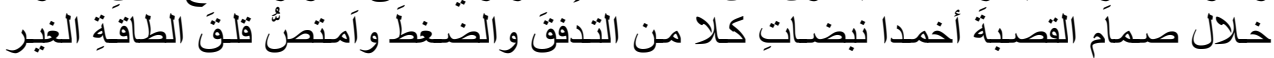

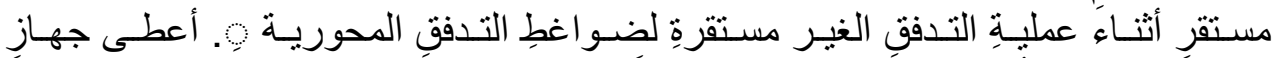

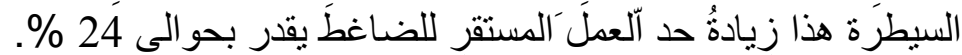

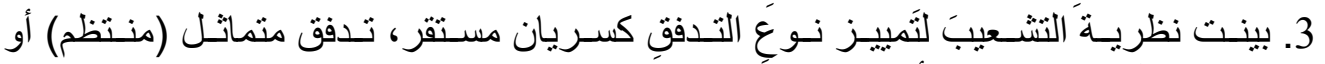

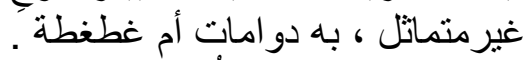

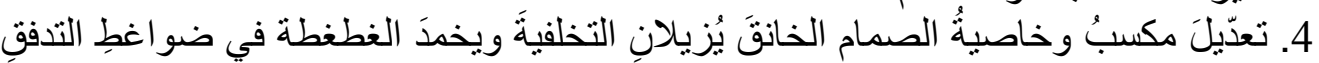
المحورية.

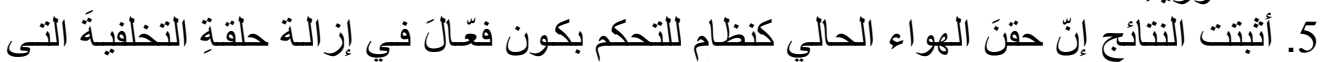

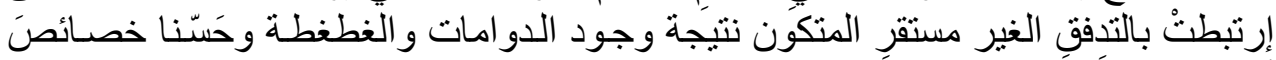

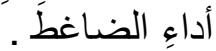
و أظهرت النتائج النظريـة تطـابق جيـد مـع النتائج المعمليـة و النظريـة لبعض نتـائج البـاحثين السابقين. 